\title{
A MOTIVATIONAL-VOLITIONAL PERSPECTIVE ON IDENTITY DEVELOPMENT
}

\author{
Peter M. Gollwitzer \\ Ute Bayer \\ Michaela Scherer \\ Andrea E. Seifert
}

In this chapter we discuss identity development from a goal implementation perspective. Identity achievement is typically (e.g., Marcia, 1980) defined as a choice between options (e.g., "Should I become a physician or a pharmacist?"). This traditional perspective ignores the fact that identity choices have to be accompanied by implementational efforts.

According to self-completion theory (Wicklund \& Gollwitzer, 1982), the implementation of identity goals persists over time, because identity goals cannot actually be completed. In addition, single failures do not stop their pursuit, but lead to enhanced striving for identity goals. A person spontaneously initiates this enhanced striving through compensatory efforts (called self-symbolizing) that focus on indicating completeness to others 
through the acquisition of relevant symbols of the identity aspired to (e.g., writing articles for a scientist, children's school grades for being a good mother). The person assigns to others the role of an audience that only has to take notice of the person's self-symbolizing efforts; no sensitive social interactions between the audience and the person are attempted or necessary (Wicklund \& Gollwitzer, 1982).

More recent research demonstrates that self-symbolizing cannot be replaced by self-esteem-enhancing strategies (Scherer, 1999). Moreover, even simply proclaiming one's intention to acquire relevant indicators of an identity creates a sense of completeness as long as these intentions are recognized by others (Seifert, 1999). Furthermore, both easy- and difficultto-acquire indicators of an identity are equally effective in creating a sense of possessing the aspired-to identity (Brunstein \& Gollwitzer, 1996). Finally, it has been demonstrated that the cognitive orientation (mind-set) associated with merely choosing identity goals differs from the mind-set associated with actually pursuing chosen identity goals (Bayer, 1998). We discuss in this chapter the implications of these findings for personality development across the life span. We suggest that old and very old people can effectively maintain their identity claims through self-symbolizing, which is facilitated by the tendency of older individuals to reduce social contacts to a few intimate friends.

\section{SELF-CONCEPT, SELF-ESTEEM, AND IDENTITY GOALS}

Theory and research on the self have a long tradition in psychology (e.g., Allport, 1943, 1955; Baumeister, 1986, 1998; Gordon \& Gergen, 1968; James, 1890/1950; Suls, 1993; Suls \& Greenwald, 1983). According to James (1890/1950), the term self (or identity). refers to a cognitive structure that incorporates all of a person's answers to the question "Who am I?" Researchers organize the answers given to this question into a number of different categories. One group of answers is related to physical attributes (e.g., "I am slim"); another is related to the broader category of social identities, which includes chosen or assigned social roles of an individual (e.g., "I am a woman"; "I am a teacher"). Finally, some answers may refer to perceived traits and dispositions (e.g., "I am tolerant"), to skills and aptitudes (e.g., "I am a math whiz kid"), or to values and interests (e.g., "I love to sail"). 
Following William James, a research tradition developed that construes the self as something the individual needs to understand, and therefore speaks of the self or identity in terms of a self-concept. There are many theoretical perspectives on how the individual perceives the self (e.g,. Bem's [1972] self-perception theory; social-interactionist approaches based on Cooley [1902] and Mead [1934], e.g., Stryker \& Statham, 1985). Self-concept research evidences a continuous debate about whether an individual has a single self-concept or multiple self-concepts. Most contemporary models, however, have adopted the assumption of multiple selves, which may be organized around specific contexts of life (e.g., Linville, 1985; Markus, 1977; Triandis, 1989). Several basic dimensions have been identified along which the multiple selves may vary (see Linville \& Carlston, 1994). A temporal dimension is present in assumptions about past, present, and future selves (e.g., Gordon, 1968; Higgins, 1987; Markus \& Nurius, 1986). A centrality dimension reflects the relative importance of different self-concepts (e.g., Gergen, 1968; Sedikides, 1995), and an evaluative dimension reflects the fact that some self-concepts are relatively positive, some are more negative, and still others are mixed (Linville, 1985, 1987; Showers, 1992).

In the self-concept research literature there are still controversies about the question of whether the self is stable or malleable (e.g., Markus \& Kunda, 1986; Swann, 1983). Self-concepts maintain a certain degree of stability over time and across contexts, as people seek information that verifies their self-views and actively resist information that challenges those views (e.g., Markus, 1977; Swann, 1983). People do not use their entire repertoires of self-concepts simultaneously. Rather, specific self-aspects are activated only when they are currently relevant (e.g., Wurf \& Markus, 1991), and thus their relative accessibility may change. Finally, there are discussions about whether the self is accurate or illusionary (e.g., Brown, 1991; Brown \& Dutton, 1995; Taylor \& Brown, 1988).

Another important branch of research focuses on how the individual evaluates his or her own self (Greenwald, 1980). This affective response is discussed in its most global form as a person's self-esteem (Rosenberg, 1965). It is commonly assumed that people have a pervasive need for high self-esteem, so discussion focuses on where this need comes from and how it is served. For instance, Greenberg, Pyszczynski, and Solomon (1986; Pyszczynski, Greenberg, \& Solomon, 1997) suggest that the terror associated with fear of death is reduced by high self-esteem. Thus they argue that fear of death is an essential source of the need for self-esteem. Baumeister 
and Tice (1990; see also Baumeister \& Leary, 1995) refer to the terror of social exclusion. Leary and Downs (1995), on the other hand, have proposed that self-esteem is a fundamental motive in human beings, linked inexorably to functioning in social groups.

Various other ideas have been offered to explain positive self-evaluations. Some researchers see a link to structural qualities of self-concepts (e.g., clarity of self-concept, Campbell, 1990; complexity of self-concept, Linville, 1987; compartmentalization of positive and negative self-knowledge, Showers, 1992; Showers \& Kling, 1996), whereas other scholars (e.g., Higgins, 1987) point out that a person's affective responses toward the self are associated with the discrepancies that he or she experiences between so-called self-guides (i.e., the ideal self or ought self) and the actual self. Finally, researchers have analyzed how relations to others affect an individual's self-evaluations. Tesser (1988) has focused, in his self-evaluation maintenance theory, on social comparison processes, whereby basking in the reflected glory of others can enhance self-esteem. Baumeister (1982), on the other hand, points to strategic self-presentation as a means of boosting one's self-evaluation.

Research on self-esteem describes the self with regard to self-evaluation processes, adding an affective and motivational dimension to self-concept research traditionally focusing on cognitive self-aspects. What the research on positive self-evaluations has not yet captured, however, is how the desired self is achieved behaviorally. It is not enough to consider how vital diverse goals are for a person's self-esteem (e.g., being a good mother may have more influence on the self-esteem than being a good skier), one also needs to consider how identity goals are achieved successfully. This goal perspective on the self has been described by Wicklund and Gollwitzer's (1982) theory of symbolic self-completion, which focuses on the implementation of self-defining goals. The person is defined as an active agent (see also Baumeister, 1998; Ford \& Lerner, 1992) who not only chooses among possible identity goals but also regulates the implementation of chosen goals. Self-completion theory focuses on goals that specify a person's desired self-definition: so-called identity goals. They are integrated in an individual's self-concept and have a lasting effect on behavior regulation.

Heckhausen (1989) and Gollwitzer (1990; Heckhausen \& Gollwitzer, 1987) have distinguished between motivational and volitional processes of wish fulfillment. Whereas motivational processes guide a person's choices among goals, volitional processes are assumed to determine a person's goal 
implementation. The former relates to issues of feasibility and desirability of potential goals (i.e., wishes and desires), whereas the latter relates to the commitment to the chosen goal and to holding on to it, even in the face of difficulties. Research on the self has traditionally been concerned with motivational issues (i.e., research on the self-concept as well as self-esteem). Self-completion theory, on the other hand, is concerned with the volitional issue of implementing identity-related (self-defining) goals.

\section{SELF-COMPLETION THEORY}

\section{Historical Roots}

Self-completion theory (Wicklund \& Gollwitzer, 1982) can be traced back to Lewin's (1926) and his students' research on goal-directed behavior. Lewin argues that when a person sets a goal for him- or herself, a quasi-need originates and a tension state comes into play that remains until the goal is reached. The tension state is linked to the person's commitment to reaching the goal. In support of Lewin's theory, it has been demonstrated that participants' interest in resuming a task remains high after their work on the task has been interrupted (Lissner, 1933; Mahler, 1933; Ovsiankina, 1928).

Further, the tension state can be reduced not only through the attainment of the original goal but also through the performance of alternative goaldirected activities. Following task interruption, Mahler (1933) gave some of her experimental participants a substitute task. This had a strong impact on the subsequent tendency to resume the original task; the resumption rate was rather curtailed. Mahler observed that when people's goals were to perform intellectual tasks (e.g., solving a mathematical problem), other quite different intellectual tasks (e.g., solving a puzzle) served as substitutes for goal attainment. Henle (1944) suggests that the concrete tasks in this Lewinian research were related to certain "superordinate" goals, such as creativity, intelligence, and ambition. It can be assumed that whenever participants saw a similarity between the quality of the original task and the quality of the substitute task, they were no longer inclined to return to the original task because substitute goal (e.g., to be creative) completion had occurred.

Mahler (1933) found that the resumption effect was strongest when the substitute task carried a "social reality." Only when the solution of the substitute task could be announced to the experimenter did the task have 
tension-reducing properties. Apparently, participants not only strove to solve the task but also wanted others to recognize their striving. Only solving the substitute tasks in a social reality situation provided the participants with a sense of having attained the self-related goal to which they aspired while working on the original task.

\section{The Concept of Self-Defining Goals}

Self-completion theory provides a theoretical framework for the analysis of striving for self-defining goals. Striving for a particular identity goal requires the execution of identity-related activities. For the self-definition of a dancer, for instance, the related activities involve a solid educational background, high-quality equipment, dancing performances, and so on. With the goal concept, the theory points to the individual's commitment to accumulating the whole set of indicators of identity attainment.

In contrast to non-self-defining goals, self-defining goals specify a desired future self or self-aspect. A non-self-defining goal (e.g., to build a tower from wooden blocks) specifies an outcome that is not related to the self. Therefore goal attainment can be judged by concrete criteria that are related to the task at hand (e.g., there are still two building stones missing). A self-defining goal, on the other hand, delineates numerous possible, culturally agreed-upon symbols. Thus progress in attaining self-defining goals (e.g., to be creative) cannot be judged by a single criterion. A common feature of self-defining goals is that they encompass a whole set of symbols that indicate progress in attaining a self-definition. This implies that when a person fails to acquire one symbol, he or she can resort to alternative routes of completing the self-definition by acquiring other symbols. In contrast, when the person tries to attain a non-self-defining goal of simply meeting the task at hand and fails, then he or she will have to complete the task by task-related means.

\section{Indicators of Completeness and} the Importance of Social Reality

The achievement of self-defining goals implies the accumulation of various relevant indicators or symbols, as each self-definition carries a number of possible indicators. For example, one can self-symbolize through fulfilling daily duties and performances associated with a particular identity (e.g., a baker bakes bread), through the acquisition of the skills 
and tools associated with a specific identity (e.g., a musician acquires certain skills in order to play an instrument), by simply making a verbal claim to possess a particular identity (e.g., "I am a psychologist"), through the exercise of identity-related social influence (e.g., an academic psychologist may engage in teaching psychology), and by displaying material symbols (e.g., a pious person may wear a golden cross).

These various forms of self-symbolizing obviously differ in terms of their accessibility. For example, it is easy to show off relevant symbols one already possesses or to claim the possession of an aspired-to identity through self-description. In contrast, the actual acquisition of relevant symbols (e.g., attaining advanced education) is more difficult. From the perspective of self-completion theory, however, not only the forms of self-symbolizing that are difficult to perform but also those that are easily attainable potentially indicate to others one's claim to possess the intended self-definition. What makes a difference is whether the chosen form of self-symbolizing has become a social fact. Self-completion theory asserts that the sense of progress toward a self-defining goal depends on the acknowledgment of others. Thus the social community has to take notice of the person's possession of indicators of the particular self-definition.

\section{The Central Hypotheses of Self-Completion}

Self-completion theory can be summarized by three central hypotheses:

1. The compensation hypothesis: Whenever a person who strives for a self-defining goal experiences a lack of relevant symbols, a sense of incompleteness arises that elicits attempts to strive for the desired identity goal through alternative routes.

2. The social reality hypothesis: Self-symbolizing that becomes a social fact is likely to be particularly effective in reducing the experienced sense of incompleteness.

3. The social insensitivity hypothesis: Self-symbolizing individuals do not address their audiences as partners for mutual exchange but as audiences that serve the sole function of taking notice of their claim to possess the aspired-to identity.

\section{The Compensation Hypothesis}

Self-completion theory postulates that an experienced lack of relevant symbols causes a sense of incompleteness. This experience may arise when 
the individual receives negative feedback about identity-related performances, when the individual compares him- or herself to others, or when the individual fails to acquire a relevant symbol. When committed people experience a sense of incompleteness, they try to symbolize completeness concerning the self-defining goal through alternative routes. As identity goals commonly imply a whole array of symbols, compensatory efforts can be expressed in any of the many alternative routes of self-symbolizing.

The compensation hypothesis has been tested in a series of experiments that used the following paradigm. Participants were students committed to a certain self-definition. The researchers made half of the participants feel incomplete by pointing out that they lacked a relevant indicator ("incomplete" participants). The other half of the participants were told that they possessed this indicator ("complete" participants). Finally, in an ostensible second experiment, the participants had a chance to acquire alternative symbols. The extent to which they used this possibility was measured.

In one experiment with graduate students enrolled in a business school, a first researcher asked the participants to fill in a questionnaire to find out whether they possessed the ideal personality profile observed in successful businesspeople (Gollwitzer, 1983). In a presumably unrelated second experiment, participants were asked to play a role in a game that simulated interactional conflicts in business conference meetings. Participants could choose one of six possible roles, ranging from chair of the board to keeper of the minutes. Shortly before participants were asked to make their choices, the first experimenter disrupted the study and gave them positive or negative personality feedback. Half of the participants were told they had personality profiles similar to the ideal profile, whereas the other half were told that their personalities were dissimilar to that of a successful businessman. Participants who received negative feedback aspired to positions of higher prestige (e.g., chair of the board) more often than did people who received positive personality feedback. From the perspective of selfcompletion theory, these findings show that the lack of one symbol of an aspired-to identity (i.e., not matching a relevant ideal personality profile) is compensated for by self-symbolizing efforts focusing on an alternative symbol (i.e., choosing a high-prestige position).

The compensation hypothesis has been supported in numerous other studies using a variety of different self-definitional symbols, for example, influencing others (Wicklund \& Gollwitzer, 1981), inventing positive self-descriptions, and refusing to admit failures (Gollwitzer, Wicklund, $\&$ Hilton, 1982). Further, incomplete participants have distanced themselves 
from unsuccessful people (Wagner, Wicklund, \& Shaigan, 1990), displayed material symbols (Wicklund \& Gollwitzer, 1982), and used prestigious tools (Braun \& Wicklund, 1989).

\section{The Social Reality Hypothesis}

Self-completion theory postulates that self-symbolizing that becomes a social fact is likely to be particularly effective in reducing a sense of incompleteness. In a first experimental paradigm, participants were given the opportunity to engage in a self-symbolizing activity, either noticed or unnoticed by others (Gollwitzer, 1986b, Studies 1 and 2). Given that identity goals are located on the level of social reality, striving for an identity in front of an audience is expected to provide a stronger sense of possessing the aspired-to identity than striving in the absence of an audience. In a new situational context, participants were given a further opportunity to strive for the aspired-to identity. If self-symbolizing noticed by others provides a stronger sense of completeness than unnoticed self-symbolizing, comparatively less striving should have been observed in participants whose symbols were noticed by others.

In the first study, female college students with the identity goal of raising a family were asked to write down personal skills relevant to their succeeding as mothers (Gollwitzer, 1986b, Study 1). They were told either that these self-descriptions would be carefully studied by partner participants or that their descriptions would not become known to others. Afterward, all participants were given the opportunity to engage in further self-symbolizing by completing a personality profile that carried a sample profile representing the ideal personality of a mother. The participants who expected that their initial self-symbolizing would not be noticed by their partners felt compelled to engage in further self-symbolizing by drawing their own profiles similar to the mother's profile provided. Participants whose initial self-descriptions would be noticed by partners, however, differed more from the ideal mother profile. In a second study, following the same logic, these effects were replicated with medical students (Gollwitzer, 1986b, Study 2). Thus it has been demonstrated that a strong sense of completeness arises when the possession of indicators of an aspired-to identity is socially realized.

A second approach is based on the idea that incomplete individuals oriented toward achieving a particular identity are likely to be especially concerned with finding an audience for their identity striving. Accordingly, 
people's readiness to engage in identity-related goal striving needs to be manipulated (i.e., incomplete, complete), and afterward their initiative in making self-symbolizing efforts noticed by others has to be observed. In a further study, medical students with the expressed intention of becoming physicians were exposed to positive or negative personality feedback regarding their prospects as physicians (Gollwitzer 1986b, Study 3). Subsequently, these participants were given the opportunity to engage in self-symbolizing by finding solutions to a series of simple medical problems. They were allowed to submit completed sections of the assignment to the experimenter whenever they desired. More than 50\% of the incomplete participants, but only $8 \%$ of the complete participants, attempted to bring their completed tasks to the experimenter's notice before they had finished the entire stack of tasks.

\section{The Social Insensitivity Hypothesis}

Knowing that self-symbolizing individuals turn to others to strengthen their sense of possessing an aspired-to identity, we have explored how self-symbolizing individuals relate to their audiences. Self-completion theory suggests that this type of relation to others is best described as a pseudo-social interaction. Self-symbolizing individuals regard their audiences as serving the sole function of taking notice of the individuals' possession of their aspired-to identities; they do not consider their audiences to be mutual exchange partners. Attributes of audiences that go beyond this purpose are largely neglected. This social insensitivity hypothesis has been tested in several experiments. Participants were told about the personal wishes and desires of their audience, posed in a way that either contradicted participants' self-symbolizing efforts or was in line with them. Afterward, it was observed how incomplete and complete participants followed the audience's wishes and desires.

Gollwitzer and Wicklund (1985) demonstrated how individuals who strive for self-completion neglect the thoughts and feelings of an audience to which their self-symbolizing efforts are directed. In one study, male undergraduates committed to various kinds of sports were first manipulated to feel either incomplete or complete through negative or positive feedback. Then they were asked to participate in a presumably second study on first impressions. The target person to be encountered was described as an attractive female undergraduate who had expressed a preference for 
getting to know either modest or proud people. Before participants were asked to introduce themselves to the target person through written self-descriptions of their strengths and weaknesses in their self-definitional areas (i.e., swimming, tennis, track), they rated their feelings of attraction toward this person. It was observed that incomplete participants produced more self-promoting descriptions than did complete participants, regardless of the target person's preference for meeting individuals with modest as opposed to proud self-descriptions. Moreover, self-symbolizing individuals ignored even their own interpersonal interests. Whereas complete participants followed the target person's self-presentational cue to the degree to which they felt attracted to her, incomplete participants' self-descriptions were completely unaffected by their feelings of attraction. In summary, self-symbolizing individuals do not seem to care much about their audience's interests. They focus on their self-definitional strengths whether the audience is present in person or not and whether the audience explicitly expresses its interests or not.

\section{PROCESSES OF SELF-COMPLETION}

\section{Mutual Exchangeability of Symbols}

Wurf and Markus (1991) claim, in accordance with self-completion theory, that failure in particular routes to achieve an identity striving will lead to enhanced rather than decreased striving. Further, they argue that symbolic validation of the self, such as positive self-descriptions, might be less satisfying than actual achievements. From the standpoint of self-completion theory, however, positive self-descriptions should be as effective in generating a sense of completeness as self-defining task performances when the given self-description is recognized by others, thereby becoming a social reality (Gollwitzer, 1986a).

This issue has been addressed directly in two experiments (Brunstein \& Gollwitzer, 1996). In one experiment, medical students were first instructed to solve simple interpersonal problems related either to conflicts that physicians commonly experience in their profession or to problems of everyday life. Afterward, participants were asked to perform a mental concentration test ( 22 test; Brickenkamp, 1981) described as measuring a skill either relevant or irrelevant to being a physician. When participants had been given failure feedback on solving the physician-related problems 
(i.e., the first task) and the second task was ostensibly a physician-related skill performance, the $d 2$ test performance peaked. When participants who received failure feedback on solving the physician-related problems (i.e., the first task) worked on the concentration test described as measuring a skill unrelated to physicians, test performance dropped. In the no-feedback conditions, performances on the $d 2$ test were at medium level and did not differ from each other. Thus identity-relevant performances are powerful indicators that individuals possess a given identity. When such indicators are not available, individuals feel highly incomplete, which causes them to strive intensively for alternative indicators, and other non-identity-related performances are hampered.

A second study investigated whether an incompleteness experience stemming from a weak identity-related performance can also be effectively reduced through self-symbolizing based on positive self-descriptions, thereby making further self-symbolizing no longer necessary (Brunstein $\&$ Gollwitzer, 1996, Study 2). Students of computer sciences were asked to perform a concept formation test, apparently to assess a number of mental skills commonly found in successful computer scientists. After receiving failure feedback or no feedback on this first task, participants were asked to perform a second task ( $d 2$ test), described as measuring a skill either relevant or irrelevant to a computer scientist. Consistent with the observation made in Study 1, participants with failure feedback performed better on the $d 2$ test than did participants with no feedback when the test was described as identity relevant. When the $d 2$ test was described as irrelevant, comparatively worse performance was observed.

After the negative feedback on the concept formation test, half of the participants were allowed by a second experimenter to describe their personalities on a semantic differential task. When they had done so, they learned from this second experimenter that they possessed personality attributes observed in successful computer scientists. This intervention completely wiped out the performance effects of the failure feedback. Whereas no-intervention participants reduced their experienced incompleteness by stepping up their performance on the identity-related $d 2$ test, incomplete participants who were told by the second experimenter that they possessed identity-relevant attributes no longer needed to do so, because their feeling of incompleteness was already reduced. This finding implies that performance-related indicators of an identity are mutually exchangeable with easily accessible indicators, such as publicly recognized positive self-descriptions. 


\section{Self-Affirmation Versus Self-Completion}

Self-defining goals may differ in terms of how strongly they serve a person's need for self-esteem (e.g., being a good student may serve a particular person's self-esteem needs more than being a good gambler). In a model of self-affirmation processes, Steele (1988; Liu \& Steele, 1986) argues that people's responses to events that threaten self-esteem are not confined to the domains in which the self-threats occur; rather, people strive toward a global sense of self-integrity. This superordinate motive enables individuals to engage in a variety of highly flexible compensation processes while they try to cope with self-threatening information. Incompleteness experiences regarding identity goals that are strongly linked to the superordinate goal of self-esteem protection and maintenance thus may be reduced not only through the achievement of self-symbolizing indicators but also through self-esteem-pampering maneuvers. From a pure self-completion theory perspective, however, even when an identity goal is strongly linked to self-esteem, the range of substitutability should be limited to the relevant identity symbols only, and should not encompass the region of protecting self-esteem. Whether self-esteem compensation (Steele, 1988) or self-completion compensation (Wicklund \& Gollwitzer, 1982) occurs is likely to be moderated by a person's feelings of commitment to the self-defining goal in question. Effective substitution, for a highly committed individual, must involve self-symbolizing in the form of acquiring or pointing to indicators of the aspired-to self-definition. If the individual feels less committed to the self-definitional goal, however, compensatory efforts may be directed only at affirming his or her self-esteem.

This question was addressed in a recent study by Scherer (1999). Law students who were either strongly or weakly committed to the self-defining goal of becoming a successful lawyer were induced to symbolic incompleteness through negative feedback. All participants were then given, in randomized order, the opportunity to both enhance their self-esteem through self-affirmation and compensate their incompleteness through symbolic self-completion. The expectation was that highly committed students who received the incompleteness manipulation should not engage in self-affirmation, but only in self-symbolizing. Weakly committed students, however, should engage in self-affirmation and fail to self-symbolize.

In the first part of the experiment, the law students' commitment to the goal of becoming a successful lawyer was measured using a questionnaire. A few weeks later, highly and weakly committed law students were 
contacted again by the experimenter and asked for an appointment. The participants were made to feel incomplete in relation to the goal of becoming a successful lawyer with the help of negative feedback. After they had filled in a questionnaire containing 10 scenarios about interpersonal conflicts in the life of a lawyer, the experimenter told them that they had solved only very few of the problems in a competent manner and that the average lawyer was much better in solving social conflicts.

After this negative feedback, all participants were given the opportunity to both enhance their self-esteem through positive self-affirmation and reach symbolic self-completion. In the self-affirmation task, participants were asked to choose their most important value out of a list (e.g., aesthetics, politics) and to write as much or as little as they wanted about why this value was so important to them. The writing was later analyzed by two independent raters with regard to different dimensions (e.g., positivity of self-presentation, self-disclosing) and an overall score for self-affirmation was formed (Tesser, Martin, \& Cornell, 1996). In the symbolic self-completion task, participants had to draw their personality profiles into a questionnaire with 10 different personality dimensions (e.g., rigid, suspicious). Before they began, the experimenter put an already finished profile of an ostensible lawyer next to the participants on the desk, telling them this was an ideal profile of a successful lawyer. Later, the similarity of the participants' profiles to the profile of the ideal lawyer was measured (Gollwitzer, 1981). The closer the students drew their profiles to that of the ideal lawyer, the more they could be considered to strive for completeness.

After the incompleteness manipulation, law students who were highly committed to the goal of becoming a successful lawyer showed a much greater approximation to the ideal lawyer's profile than did weakly committed law students. It did not matter whether or not they had a chance to enhance their self-esteem through the self-affirmation procedure. Self-affirmation was, on the other hand, observed less in highly committed than in weakly committed participants. Self-affirmation was not used by highly committed participants and thus does not seem to be an alternative way to reach symbolic self-completion. In other words, if people are highly committed and are made incomplete concerning their self-defining goals, the only way they can reach self-completion is through self-symbolizing in the form of acquiring or pointing to indicators of the aspired-to identity. On the other hand, if individuals are only weakly committed to their 
self-defining goal and receive negative feedback, they use self-affirmation to restore their lowered self-esteem.

\section{Intended Behaviors as Symbols}

One of the core assumptions of self-completion theory is the substitutability of indicators of completeness. Different types of symbols can be used in a flexible manner. One type of symbolizing is to engage in positive self-descriptions (Brunstein \& Gollwitzer, 1996). It seems possible, therefore, that effective self-descriptions can also take the form of expressed intentions. In this case, self-descriptions would have to specify relevant behavioral goals that the person intends to realize in the future. If the behavioral goal is related to a self-definition, the social realization of the intention should lead to a less intensive subsequent execution of the intended action, however. This is because the publicly expressed intention leads to a higher state of completeness, which in turn reduces motivation to acquire additional symbols, such as to actually perform the behavioral goal. Thus the social realization of behavioral intentions related to a given self-definition should reduce the tension state that originates from the experience of incompleteness. This assumption was examined in two experiments.

In the first experiment, psychology students had to fill in several questionnaires (Dyes, 1984). The first one measured students' commitment to the self-defining goal of becoming a clinical psychologist ("clinicians" versus "nonclinicians"). A second questionnaire was aimed at the level of clinical knowledge and training, and induced a state of incompleteness by asking only questions that participants had to answer in the negative (e.g., "Do you have a therapy license?"). In a third questionnaire, participants were asked to give their opinions on different statements. In the critical statement, they had to respond on a 5-point scale to the sentence "I would like to watch therapy videos to learn more about therapy techniques." Thus the degree of an existing intention was measured, and for the rest of the study only participants with a strong intention were of interest. Finally, the intention to watch therapy videos was either acknowledged by the experimenter (social reality) or remained unnoticed (no social reality). In an ostensible second experiment, the participants' task was to observe the interaction between a therapist and a client (shown on a video), to count how often they made eye contact, and to rate the mood between therapist and client. Participants were told that their time was limited to 40 minutes, 
but they should feel free to finish earlier if they wanted to. The dependent measure was the time participants worked on the task.

Students committed to become therapists who had expressed the intention to analyze therapy videos and whose intention was acknowledged by the experimenter finished the task earlier than those in the no-social-reality condition (i.e., the intention was not acknowledged by the experimenter). The amount of time noncommitted students spent on the task was in between the two committed conditions, and there was no difference whether their intention was socially realized or not. Thus if a person is highly committed to a self-defining goal, the social realization of relevant behavioral intentions can entail a disinterest in pursuing the intended behavioral goal, because the tension state is reduced and the person has no need for acquiring additional symbols.

A question that comes to mind is whether the behavioral intention is translated into action despite social realization if people form implementation intentions in addition to goal intentions. The distinction between goal intentions and implementation intentions has been suggested by Gollwitzer (1993). It has been demonstrated that goal intentions ("I intend to show behavior X!") are less successful in guiding a person's actions than are implementation intentions ("I intend to initiate the goal-directed behavior X, when situation $\mathrm{Y}$ is encountered!"), especially when the goal is difficult to attain (Gollwitzer \& Brandstätter, 1997; Gollwitzer \& Schaal, 1998). Gollwitzer suggests that implementation intentions are particularly effective, because they link intended goal-directed behaviors to anticipated situational cues and thus induce direct automatic control of the intended behaviors through these cues. Thus, by forming implementation intentions, people pass on control of goal-directed activities from the self to the environment. For this reason, implementation intentions may not suffer the negative consequences that are observed with the social realization of goal intentions.

An experiment was conducted to test this assumption (Seifert, 1999). In the first part of the study, first-year law students committed to the self-defining goal of becoming a successful lawyer were asked to complete several questionnaires. In the first questionnaire their level of knowledge in law was measured and incompleteness was induced by reminding them of their deficient knowledge. Participants were then asked to give their opinions about several statements, one of them either formulated as a goal intention ("I intend to make best use of my present education") or as an implemen- 
tation intention ("I intend to make best use of my present education. And each time I see an opportunity to intensify my studies, I seize it"). Again, only participants who strongly agreed with this statement were included in the analysis. Afterward, the intention was noticed by the experimenter or remained unnoticed. In a presumed second experiment, participants finally had the chance to realize their intention by solving 20 criminal law cases, which was an opportunity to improve their knowledge in law. The students were given 45 minutes to work on these cases, but they were allowed to finish earlier. The time participants spent on working was used as the measure of translating their intentions into behavior.

In the goal intention condition, the results of the first study were replicated. Participants whose intentions had become a social reality finished their work earlier than did participants whose intentions stayed unnoticed. In the implementation intention condition, social reality made no difference with respect to the time spent on solving the presented cases. Participants in both social reality conditions (i.e., participants' intentions were either noticed by the experimenter or stayed unnoticed) worked close to as long as possible, and thus did not differ from each other. This pattern of data demonstrates that the negative behavioral effects of the social realization of goal intentions vanish when goal intentions are furnished with implementation intentions. Apparently, when action control is delegated to environmental cues via implementation intentions, action is no longer affected by the reduced tension state stemming from the social realization of the respective goal intention.

Both of the two studies reported demonstrate that goal intentions that become a social fact can serve self-definitional functions. As a consequence, the person is less motivated to perform the intended behavior. However, this negative effect does not occur when a person has formed additional implementation intentions. This discovery has important implications for research on the intention-behavior relation. In his theory of planned behavior, Ajzen (1985) suggests that the strength of an intention (resulting from its feasibility and desirability) determines how well it is translated into behavior. But even a strong goal intention should fail to be implemented whenever a person has mentioned it to others and this social realization has led to completeness with respect to an identity goal to which the person feels committed. Only when additional implementation intentions are formed should the strength of the intention guarantee its translation into behavior. 


\section{From Incompleteness to Completeness: A Process Account}

Participants were asked in some recent studies about their feelings after they had experienced failure on an identity-relevant task (Brunstein \& Gollwitzer, 1996). They reported feeling more worried, pessimistic, dissatisfied, and blocked than after failing in an identity-irrelevant task. Frustration and ruminative self-concerns over a poor identity-relevant performance, however, changed into an energetic feeling when participants were given a second chance and when this second task was described as identity relevant. If the second task was described as identity irrelevant, however, participants continued to worry. It seems that incompleteness experiences are highly frustrating only until an opportunity for compensation arises, which immediately converts this severe burden on an individual's striving for identity into an energized feeling. Self-symbolizing, thus, is an actionoriented state in which attention rests solely on successful compensation.

Flüge and Gollwitzer (1986) analyzed the impulsiveness of self-symbolizers by giving incomplete and complete participants an opportunity to compensate their feeling of incompleteness immediately to an audience that was highly critical of participants' identity-related potentials or to a more accepting audience at a later point in time. They found that incomplete participants preferred to self-symbolize in front of the immediately accessible audience, whereas complete participants waited for the more accepting audience. Similarly, it has been demonstrated that even a mere goal intention, mentioned to another person (e.g., experimenter), can be a highly effective way to self-symbolize (Dyes, 1984; Seifert, 1999). Thus incomplete individuals' main interest is directed at documenting the aspired-to identity in front of others. However, one needs to keep in mind that opportunities merely to enhance self-esteem are of little use to the incomplete person. The impulsiveness of self-symbolizers does not lead them to engage in any possible activity that may reduce dissatisfaction. It has been documented that incomplete individuals engage only in self-enhancing activities that guarantee completeness with respect to their self-defining goals (Scherer, 1999).

\section{The Choice of Identity Goals}

In a historical analysis of human identity, Baumeister (1986) has suggested that society no longer assigns identity to its members, but instead forces individuals to create their own identities. Baumeister argues that 
identity achievement has become a struggle for the individual, because every person has to decide who he or she wants to be. Furthermore, to realize one's choice, willful effort is necessary. For instance, becoming an athlete, a physician, or a religious person requires a decision and necessitates acts to implement that decision.

Even though self-completion theory acknowledges the making of an identity choice as a prerequisite to diligent willful pursuit of identity, it focuses primarily on the implementation of a chosen identity goal. To describe the complete process of the willful pursuit of identity, one must definitely also address how people commit themselves to certain identities. Developmental psychologists, following Erikson's (1956) ideas on identity development, have addressed this issue. It is assumed that the experience of an identity crisis leads to vigorous deliberations (e.g., Marcia, 1966, $1967,1980)$. The individual is torn between possible options and therefore continues weighing alternatives until a definite identity commitment is formed.

Ruble (1994) has analyzed identity crises in periods of change or transition (e.g., the transition to junior high school). She presents a model of transition with three different phases, each associated with a distinct orientation toward social information. In the first phase, a person faces a new situation in which old categories and expectations are no longer applicable. Therefore, the person engages in an active search among a range of possible self-constituents. As soon as the individual acquires some basic knowledge, a second phase of consolidation begins, in which the person weighs and considers consequences for his or her own ego (e.g., "What kind of a mother would I be?"). In the third phase, those new identities are integrated into the already existing self-concept. In addition, unexpected events during the life cycle (e.g., an unexpected pregnancy) make it necessary for the individual to choose among new identities (e.g., to be a mother; Lydon, Dunkel-Schetter, Cohan, \& Pierce, 1996).

One of the most interesting aspects of self-completion theory is the psychological difference between individuals searching for an identity and self-symbolizing individuals (Gollwitzer, 1986b). Individuals searching for an identity display open-minded information processing. Maccoby and her colleagues found that women with babies were much more likely to read a booklet on child care that they got through the mail, to gather information, and to discuss it with others, compared with women with older children or women who did not have babies (see Maccoby, Maccoby, Romney, \& Adams, 1961; Maccoby, Romney, Adams, \& Maccoby, 1959). 
It is assumed that a woman with a newborn is still in the process of searching for the identity of a mother. Similar conclusions concerning women's information seeking have been presented in a cross-sectional study by Deutsch, Ruble, Fleming, Brooks-Gunn, and Stangor (1988).

While an individual is searching for an identity, his or her cognitive orientation is characterized by open-mindedness. Once that person has committed him- or herself to a specific identity, however, the closed-mindedness of self-symbolizing sets in (Brunstein \& Gollwitzer, 1996). Self-symbolizing individuals seem to be immune to questioning their identity choices. Identity failures lead to experiences of incompleteness associated with ruminative thoughts; however, when an opportunity to self-symbolize arises, ruminative thoughts are immediately put aside and a sole focus on performing self-symbolizing actions occurs. In this sense, the cognitive orientation of self-symbolizing individuals is comparable to the implemental mind-set (Gollwitzer, 1990; Gollwitzer \& Bayer, 1999) that has been observed in individuals who plan the implementation of goal-directed actions. In an implemental mind-set, people process information on the execution of goal-directed actions more readily and effectively (Gollwitzer, Heckhausen, \& Steller, 1990, Study 1). Moreover, an implemental mindset also produces biased inferences, in the sense that people have stronger positive illusions about their personal attributes and skills (Taylor \& Gollwitzer, 1995) and they experience illusionary feelings of control in uncontrollable situations (Gollwitzer \& Kinney, 1989).

However, the willful pursuit of identity goals (e.g., to become a clinical psychologist) sometimes creates new occasions for deliberation (e.g., to choose among different kinds of therapies). On each of these occasions, it is important to obtain precise desirability-related and feasibility-related information (e.g., whether one's skills are sufficient). In short, a precise analysis of the diverse options is required. With regard to such deliberations, it is not useful to keep up a positive illusion about one's personal attributes and skills; rather, a realistic self-view is called for.

Bayer (1999) examined the assumption that people committed to identity goals are able to regain open-mindedness in the face of upcoming identity-related decisions. Students were confronted with the opportunity to obtain information on their possible weaknesses and strengths in both intellectual (relevant to "student" identity) and athletic (irrelevant to "student" identity) abilities. They had to indicate their interest in each piece of information by marking those questions (on a list of 14) they wanted to 
have answered. Prior to this, the participants took part in a presumably independent study in which different mind-sets had been established. To induce a deliberative mind-set, half of the participants had been asked to name a personal goal conflict (e.g., "Should I take part in an examination now or later?"), to list the diverse advantages and disadvantages, and to reflect on the likelihood of their occurrence. In addition, they had to think of potential difficulties that might arise. To induce an implemental mindset, the other half of the participants were asked to name a concrete project on which they had already decided (e.g., to write a term paper) but had not yet started implementation. They were asked to describe the five most important steps toward its realization. Furthermore, they had to specify when, how, and where they would do so. It was expected that individuals in an implemental mind-set would prefer information about their strengths in order to create a positive self-description for their student identity. It was assumed that participants in a deliberative mind-set, in contrast, would attain accurate self-evaluations by choosing, in an evenhanded manner, positive and negative information about their identity-relevant abilities.

Participants' searches for information depended on their mind-sets. They wanted to know more about the strengths than the weaknesses of their intellectual abilities when they were in an implemental mind-set. Participants in a deliberative mind-set, on the other hand, were interested in information on both strengths and weaknesses alike. The tendency toward positively distorted information processing in order to create an identityrelevant positive self-description (as evidenced in the implemental mindset) was replaced by an open-minded, well-balanced search for information in a deliberative mind-set. These differences concerning the positivity of the preferred information were observed only with regard to intellectual abilities (relevant to "student" identity), however. All students displayed open-mindedness in looking for information concerning identity-irrelevant abilities (athletics). Positively distorted information processing was observed with regard to identity-relevant abilities only in an implemental mind-set. But a deliberative mind-set managed to interfere with this tendency and led to a balanced search for information concerning identityrelevant abilities.

In general, identity choices are associated with a cognitive orientation of open-mindedness, whereas identity pursuit is characterized by a closedmindedness that favors a self-serving search for information about relevant self-aspects. But even if a person is strongly committed to his or her identity 
goal, open-minded information processing seems possible if needed (e.g., for choices between different implemental routes). The individual has only to develop a deliberative mind-set.

\section{LIFE-SPAN PSYCHOLOGY}

\section{The Endurance of Self-Defining Goal Pursuit}

An identity goal is probably best described as a claim to possess a designated identity that is indicated by the possession of relevant symbols (e.g., owning status symbols, being able to execute relevant actions). Thus realizing an identity goal implies a continued accumulation of relevant indicators, and its pursuit is not finished simply because a powerful indicator has been acquired. Self-symbolizing becomes necessary again as soon as the lack of other alternative indicators becomes salient. Even when a person possesses extremely powerful symbols, such as many years of experience in a given field, he or she can easily be made to feel incomplete, as demonstrated by many self-completion experiments (see Wicklund \& Gollwitzer, 1982).

There are many factors that cause a constant striving for identity goals. When people progress with respect to the pursuit of an identity goal, they gain increased competence in a given field, and new horizons with a host of new, more sophisticated indicators open up. Most professional identities include arrays of symbols associated with different sections of the life course, and social and physical surroundings change while the person progresses in his or her field (e.g., the identity of a scientist is defined differently during the phases of university training, an assistant professor position, and full professorship). In addition, the social community defines the indicators for a certain identity and thus guides individuals in their goal pursuits. But from time to time such definitions are also modified (e.g., 20 years ago a person could easily indicate the identity of a scientist without having to refer to a laboratory filled with computers, but today this hardly seems possible). Finally, even an age-related decline in skills and resources (Baltes \& Baltes, 1990) is not likely to stop a person's identity striving. Older self-symbolizers can refer to performances achieved in the past through positive self-descriptions (i.e., engage in easily accessible, "accommodated" self-symbolizing; Brandtstädter \& Greve, 1994). This allows them to remain in the field without giving up their aspired-to identities. Brunstein and Gollwitzer (1996) have demonstrated that this kind of easily 
accessible self-symbolizing is as successful as self-symbolizing that is based on skillful performance.

Under certain circumstances, people do give up on identity goals. In their notion of contingent action path, Raynor and Entin (1982) have suggested that a person can move on to the next step of the path only when he or she has been successful in a more immediate step. Raynor (1982, pp. 287-288) points out that self-relevant failure in a contingent path not only means a negative identity achievement and a feeling of incompleteness, it also reduces options to acquire further indicators of the aspired-to identity (e.g., when a law student fails to earn his diploma and therefore cannot move along the path of striving for his chosen professional career). Under such circumstances, failure might prompt a reappraisal of identity goals and instigate disengagement.

Moreover, when the social surroundings of people do not support their self-symbolizing as a claim to possess given identities, self-symbolizing will not become a social fact and, consequently, will not be very effective (e.g., when a young lawyer who comes from a family of artists arrives home for a family event in his three-piece suit, the relatives may fail to recognize its symbolic character and focus instead on the aesthetic quality of the fabric). However, the symbolic world of most self-definitions involves culturally shared knowledge, and self-symbolizing is usually successful. Accordingly, failure to attain social reality is more likely to occur when self-definitions are shared only within certain narrowly defined subcultures (e.g., Hare Krishnas).

Conflict between identity goals seems to be the most powerful force for disengagement processes, such as the conflict that women experience when they are torn between the roles of mother and professional (Barnett \& Baruch, 1985; McBride, 1990). Identity goals conflict when they compete for one and the same opportunity to acquire relevant symbols. For example, a free Saturday afternoon is highly conducive not only to a person's finishing a scientific manuscript but also to her playing with her children. If she constantly chooses to play with her children, the female professional is likely to begin to disengage from her identity goal of being a professional.

A key factor for people's disengagement from identity goals seems to be a lack of access or a refusal to make use of opportunities to acquire relevant symbols; frequent experiences of incompleteness would seem to be less relevant. In the face of failure, committed individuals are oriented toward symbolizing the possession of the aspired-to identity and focus on effective acquiring and pointing to alternative indicators of completeness, rather 
than being concerned with negative outcome expectations. However, individuals sometimes need to be discouraged in their pursuit of self-definitions, and it is necessary to direct them away from self-symbolizing (e.g., a youngster with no mathematical talents who wants to become a physicist). Oettingen (1996) suggests that people start to consider negative expectations of success when they are made to mentally contrast their positive fantasies of the future with negative aspects of the present reality that stand in the way of their reaching this positive future (see also Oettingen, Chapter 11 , this volume).

\section{Compensating for Age-Related Declines}

In life-span psychology, the different ways older people deal with age-related deficits leading to a skill-demand mismatch have been described (e.g., Bäckman \& Dixon, 1992; Brandtstädter, Wentura, \& Greve, 1993). The "selective optimization with compensation" model presented by Baltes and Baltes (1990; Marsiske, Lang, Baltes, \& Baltes, 1995) portrays lifespan development as a dynamic interaction between gains and losses. When the skill-demand mismatch exceeds a certain threshold, the aging person may begin to select and thereby narrow the range of domains or goals for continued development. Second, the person may try to optimize his or her performances within this narrow domain through training, practice, and motivational enhancement. As a last resort, due to compensation strategies, the person may minimize age-related losses and limits by relying on alternative internal or external resources. For instance, a scientist suffering age-related losses of memory may first try to ameliorate the skill-demand mismatch by limiting his research to certain themes that are very familiar. Then he may attempt to acquire and maximize mnemonic skills that are particularly conducive to his field of interest. Finally, he may even actively compensate for the memory deficits by employing all kinds of substitutes, such as a skilled research assistant.

This model's implications for self-completion processes extend to the notion of gains and losses. The losses of compensation, not addressed in self-completion theory so far, become immediately apparent when one considers, for example, a person who focuses primarily on positive self-descriptions. This person fails to develop his or her identity-related performance potential. On the other hand, self-completion theory has implications for understanding the compensation notion prevalent in life-span psychology, by stressing the distinction between the inner goal of the 
self-symbolizing individual and the outer goal considered by researchers. For an individual's inner goal, it does not matter whether positive self-descriptions or self-definitional performances are used. The person advances equally well with respect to the inner goal of indicating the possession of an identity to others. For a life-span psychologist who considers the outer goal of attaining an identity, however, the self-symbolizer who employs only self-descriptions and no actual achievement does not advance at all.

\section{Social Contact Across the Life Span}

Carstensen $(1992,1998)$ postulates in her theory of socioemotional selectivity that people's reasons for social contact change during the life span. In infancy, and again in old age, people pursue emotional experiences and regulation in their social contacts. In adolescence and middle age, social contact serves the purpose of people's learning more about the self, the world, and other people. These different reasons for contact have consequences for the kinds of social encounters a person prefers. Because emotional regulation and satisfaction are more easily achieved if one is surrounded by a few intimates, Carstensen suggests that older people are likely to engage in social contact with a few intimate friends rather than get to know new people.

It could be demonstrated (see above) that the social contacts of the self-symbolizer serve the purpose of social recognition of the possession of an aspired-to identity. Social psychologists have observed that people in general prefer to abstain from conveying negative feedback to others (Blumberg, 1972; Tesser \& Rosen, 1975). Strangers, however, may tend to challenge an individual's sense of self-definitional completeness (e.g., out of ignorance) and are thus a potential source of incompleteness experiences. Compared with strangers, a person's intimates should know the self-definitions the person aspires to and thus should refrain from questioning his or her possession of a particular self-definition. In addition, intimates know about the self-definitional indicators the individual has acquired in the past. This knowledge allows the self-symbolizer to refer to these achievements in positive self-descriptions if incompleteness experiences should arise.

It appears, then, that intimate friends provide a narrow and stable social reality that makes it easy to self-symbolize effectively. For older individuals who have a rather low sense of completeness due to age-related declines in skills and resources, the tendency to focus on a narrow and stable social 
reality is likely to be particularly pronounced. In other words, older people may focus their social contacts on a few intimate friends not only for reasons of enjoyment and more effective emotion regulation (Carstensen, 1992), but also because this allows them to maintain the identities to which they have aspired throughout their lives, despite age-related declines in relevant skills and resources.

\section{SUMMARY AND CONCLUSION}

In this chapter we have described the ongoing, goal-oriented processes directed toward attaining a self-definition (e.g., being a successful businessperson, a good mother, a lawyer). From the perspective of self-completion theory, these processes consist of the continuous accumulation of relevant symbols or indicators (e.g., positive self-descriptions, relevant performances, possession of relevant status symbols) of goal attainment. We have presented research that reveals the basic principles that govern this goal pursuit. We have demonstrated that one symbol can compensate for the lack of another symbol in the sense that the various symbols of any given self-definition relate to each other as substitutes (compensation principle). We have also pointed out that others play a crucial role with respect to the effectiveness of self-symbolizing (social reality principle). Furthermore, we have documented that self-symbolizing individuals ignore their audiences' interests (social insensitivity principle). Self-affirming strategies have been shown to fail to substitute for self-symbolizing efforts because the latter require the acquisition of identity-related symbols. In addition, we have demonstrated that positive self-descriptions and the expression of identityrelated behavioral intentions can serve as symbols when they become noticed by others, thus impairing effective task pursuit. This negative effect can be eliminated, however, through the formation of implementation intentions. Moreover, we have pointed out that the choice of self-defining goals is governed by principles that are quite different from those that govern the pursuit of these goals.

Finally, we have discussed the implications of self-completion theory for life-span psychology. Old and very old people may turn to easily accessible forms of self-symbolizing (e.g., referring to relevant successes in the past) and forget about less accessible forms (e.g., demonstrating identity-relevant skills), as both forms of self-symbolizing tend to be equally effective. This allows old and very old people to feel still in possession of their aspired-to 
identities despite age-related declines in performance. Furthermore, the social reality principle suggests that reducing social contacts to a few intimate friends makes it easier for older people to self-symbolize effectively and thus to maintain their claims of possessing their aspired-to identities.

\section{REFERENCES}

Ajzen, I. (1985). From intentions to actions: A theory of planned behavior. In J. Kuhl \& J. Beckmann (Eds.), Action control: From cognition to behavior (pp. 1139). New York: Springer.

Allport, G. W. (1943). The ego in contemporary psychology. Psychological Review, 50, 451-478.

Allport, G. W. (1955). Becoming. New Haven, CT: Yale University Press.

Bäckman, L., \& Dixon, R. A. (1992). Psychological compensation: A theoretical framework. Psychological Bulletin, 112, 259-283.

Baltes, P. B., \& Baltes, M. M. (1990). Psychological perspectives on successful aging: The model of selective optimization with compensation. In P. B. Baltes \& M. M. Baltes (Eds.), Successful aging: Perspectives from the behavioral sciences (pp. 134). New York: Cambridge University Press.

Barnett, R. C., \& Baruch, G. K. (1985). Women's involvement in multiple roles and psychological distress. Journal of Personality and Social Psychology, 49, 135-145.

Baumeister, R. F. (1982). A self-presentational view of social phenomena. Psychological Bulletin, 91, 3-26.

Baumeister, R. F. (1986). Identity: Cultural change and the struggle for self. New York: Oxford University Press.

Baumeister, R. F. (1998). The self. In D. T. Gilbert, S. T. Fiske, \& G. Lindzey (Eds.), Handbook of social psychology (Vol. 2, pp. 680-740). New York: McGraw-Hill.

Baumeister, R. F., \& Leary, M. R. (1995). The need to belong: Desire for interpersonal attachments as a fundamental human motivation. Psychological Bulletin, 117, 497-529.

Baumeister, R. F., \& Tice, D. M. (1990). Anxiety and social exclusion. Journal of Social and Clinical Psychology, 9, 165-195.

Bayer, U. (1999). Der Einfluss der Bewußtseinslage des Abwägens und Planens auf die soziale Urteilsbildung. Unpublished doctoral dissertation. Universität Konstanz, Germany.

Bem, D. J. (1972). Self-perception theory. In L. Berkowitz (Ed.), Advances in experimental social psychology (Vol. 6, pp. 1-62). San Diego, CA: Academic Press.

Blumberg, H. H. (1972). Communication of interpersonal evaluations. Journal of Personality and Social Psychology, 23, 157-162. 
Braun, O. L., \& Wicklund, R. A. (1989). Psychological antecedents of conspicuous consumption. Journal of Economic Psychology, 10, 161-187.

Brandtstädter, J., \& Greve, W. (1994). The aging self: Stabilizing and protective processes. Developmental Review, 14, 52-80.

Brandtstädter, J., Wentura, D., \& Greve, W. (1993). Adaptive resources of the aging self: Outlines of an emerging perspective. International Journal of Behavioral Development, 16, 232-349.

Brickenkamp, R. (1981). Test d2 (4th ed.). Göttingen, Germany: Hogrefe.

Brown, J. D. (1991). Accuracy and bias in self-knowledge. In C. R. Snyder \& D. R. Forsyth (Eds.), Handbook of social and clinical psychology: The health perspective (pp. 158-178). New York: Pergamon.

Brown, J. D., \& Dutton, K. A. (1995). Truth and consequences: The costs and benefits of accurate self-knowledge. Personality and Social Psychology Bulletin, $21,1288-1296$.

Brunstein, J. C., \& Gollwitzer, P. M. (1996). Effects of failure on subsequent performance: The importance of self-defining goals. Journal of Personality and Social Psychology, 70, 395-407.

Campbell, J. D. (1990). Self-esteem and clarity of the self-concept. Journal of Personality and Social Psychology, 59, 538-549.

Carstensen, L. L. (1992). Social and emotional patterns in adulthood: Support for socioemotional selectivity theory. Psychology and Aging, 7, 331-338.

Carstensen, L. L. (1998). A life-span approach to social motivation. In J. Heckhausen \& C. S. Dweck (Eds.), Motivation and self-regulation across the life-span (pp. 341-364). New York: Cambridge University Press.

Cooley, C. H. (1902). Human nature and the social order. New York: Scribner.

Deutsch, F. M., Ruble, D. N., Fleming, A., Brooks-Gunn, J., \& Stangor, C. S. (1988). Information-seeking and maternal self-definition during the transition to motherhood. Journal of Personality and Social Psychology, 55, 420-431.

Dyes, A. (1984). Effekte sozialer Realisierung einer Intention auf ibre Ausfübrung. Unpublished master's thesis, Ruhr-Universität Bochum, Germany.

Erikson, E. H. (1956). The problem of ego-identity. Journal of the American Psychoanalytic Association, 4, 56-121.

Flüge, R., \& Gollwitzer, P. M. (1986, April). Volitionale Aspekte der Selbstergänzung. Vortrag auf dem 3. Workshop der Fachgruppe Sozialpsychologie, Erlangen, Germany.

Ford, D. H., \& Lerner, R. M. (1992). Developmental systems theory: An integrative approach. Newbury Park, CA: Sage.

Gergen, K. J. (1968). Personal consistency and presentation of self. In C. Gordon \& K. J. Gergen (Eds.), The self in social interaction (Vol. 1, pp. 299-308). New York: John Wiley.

Gollwitzer, P. M. (1981). The social reality of self-symbolizing: Winning completeness through others. Unpublished doctoral dissertation, University of Texas at Austin. 
Gollwitzer, P. M. (1983, July). Audience anxiety and symbolic self-completion. Paper presented at the International Conference on Anxiety and Self-Related Cognition, Berlin.

Gollwitzer, P. M. (1986a). The implementation of identity intentions: A motivational-volitional perspective on symbolic self-completion. In F. Halisch \& J. Kuhl (Eds.), Motivation, intention, and volition (pp. 349-369). Heidelberg: Springer.

Gollwitzer, P. M. (1986b). Striving for specific identities: The social reality of self-symbolizing. In R. F. Baumeister (Ed.), Public self and private self (pp. 143159). New York: Springer-Verlag.

Gollwitzer, P. M. (1990). Action phases and mind-sets. In E. T. Higgins \& R. M. Sorrentino (Eds.), Handbook of motivation and cognition: Foundations of social behavior (Vol. 2, pp. 53-92). New York: Guilford.

Gollwitzer, P. M. (1993). Goal achievement: The role of intentions. European Review of Social Psychology, 4, 141-185.

Gollwitzer, P. M., \& Bayer, U. (1999). Deliberative versus implemental mind-sets in the control of action. In S. Chaiken \& Y. Trope (Eds.), Dual-process theories in social psychology (pp. 403-422). New York: Guilford.

Gollwitzer, P. M., \& Brandstätter, V. (1997). Implementation intentions and effective goal pursuit. Journal of Personality and Social Psychology, 73, 186-199.

Gollwitzer, P. M., Heckhausen, H., \& Steller, B. (1990). Deliberative and implemental mind-sets: Cognitive tuning toward congruous thoughts and information. Journal of Personality and Social Psychology, 59, 1119-1127.

Gollwitzer, P. M., \& Kinney, R. F. (1989). Effects of deliberative and implemental mind-sets on illusion of control. Journal of Personality and Social Psychology, 56, 531-542.

Gollwitzer, P. M., \& Schaal, B. (1998). Metacognition in action: The importance of implementation intentions. Personality and Social Psychology Review, 2, 124-136.

Gollwitzer, P. M., \& Wicklund, R. A. (1985). Self-symbolizing and the neglect of others' perspectives. Journal of Personality and Social Psychology, 48, 702-715.

Gollwitzer, P. M., Wicklund, R. A., \& Hilton, J. L. (1982). Admission of failure and symbolic self-completion: Extending Lewinian theory. Journal of Personality and Social Psychology, 43, 358-371.

Gordon, C. (1968). Self-conceptions: Configurations of content. In C. Gordon \& K. J. Gergen (Eds.), The self in social interaction (Vol. 1, pp. 115-136). New York: John Wiley.

Gordon, C., \& Gergen, K. J. (Eds.). (1968). The self in social interaction. New York: John Wiley.

Greenberg, J., Pyszczynski, T., \& Solomon, S. (1986). The causes and consequences of a need for self-esteem. In R. F. Baumeister (Ed.), Public self and private self (pp. 189-212). New York: Springer-Verlag.

Greenwald, A. G. (1980). The totalitarian ego: Fabrication and revision of personal history. American Psychologist, 35, 603-618.

Heckhausen, H. (1989). Motivation und Handeln. Berlin: Springer. 
Heckhausen, H., \& Gollwitzer, P. M. (1987). Thought contents and cognitive functioning in motivational versus volitional states of mind. Motivation and Emotion, 11, 101-120.

Henle, M. (1944). The influence of valence on substitution. Journal of Psychology, 17, 11-19.

Higgins, E. T. (1987). Self-discrepancy: A theory relating self and affect. Psychological Review, 94, 319-340.

James, W. (1950). The principles of psychology (Vol. 1). New York: Dover. (Original work published 1890)

Leary, M. R., \& Downs, D. (1995). Interpersonal functions of the self-esteem motive: The self-esteem system as a sociometer. In M. Kernis (Ed.), Efficacy, agency, and self-esteem (pp. 123-144). New York: Plenum.

Lewin, K. (1926). Vorsatz, Wille und Bedürfnis. Psychologische Forschung, 7, 330-385.

Linville, P. W. (1985). Self-complexity and affective extremity: Don't put all your eggs in one cognitive basket. Social Cognition, 3, 94-120.

Linville, P. W. (1987). Self-complexity as a cognitive buffer against stress-related illness and depression. Journal of Personality and Social Psychology, 52, 663-676.

Linville, P. W., \& Carlston, D. E. (1994). Social cognition of the self. In P. G. Devine \& D. Hamilton (Eds.), Social cognition: Impact on social psychology (pp. 143193). San Diego, CA: Academic Press.

Lissner, K. (1933). Die Entspannung von Bedürfnissen durch Ersatzhandlungen. Psychologische Forschung, 18, 218-250.

Liu, T. J., \& Steele, C. M. (1986). Attributional analysis as self-affirmation. Journal of Personality and Social Psychology, 51, 531-540.

Lydon, J., Dunkel-Schetter, C., Cohan, C. L., \& Pierce, T. (1996). Pregnancy decision making as a significant life event: A commitment approach. Journal of Personality and Social Psychology, 71, 141-151.

Maccoby, E. E., Maccoby, N., Romney, A. K., \& Adams, J. S. (1961). Social reinforcement in attitude change. Journal of Abnormal and Social Psychology, $63,109-115$.

Maccoby, N., Romney, A. K., Adams, J. S., \& Maccoby, E. E. (1959). "Critical periods" in seeking and accepting information. American Psychologist, 14, 358.

Mahler, W. (1933). Ersatzhandlungen verschiedenen Realitätsgrades. Psychologische Forschung, 18, 27-89.

Marcia, J. E. (1966). Development and validation of ego-identity status. Journal of Personality and Social Psychology, 3, 551-558.

Marcia, J. E. (1967). Ego-identity status: Relationship to change in self-esteem, general maladjustment, and authoritarianism. Journal of Personality, 35, 119133.

Marcia, J. E. (1980). Identity in adolescence. In J. Adelson (Ed.), Handbook of adolescent psychology (pp. 159-187). New York: John Wiley.

Markus, H. (1977). Self-schemata and processing information about the self. Journal of Personality and Social Psychology, 35, 63-78. 
Markus, H., \& Kunda, Z. (1986). Stability and malleability of the self-concept. Journal of Personality and Social Psychology, 51, 858-866.

Markus, H., \& Nurius, P. (1986). Possible selves. American Psychologist, 41, 954-969.

Marsiske, M., Lang, F. B., Baltes, P. B., \& Baltes, M. M. (1995). Selective optimization with compensation: Life-span perspectives on successful human development. In R. A. Dixon \& L. Bäckman (Eds.), Compensating for psychological deficits and declines: Managing losses and promoting gains (pp. 35-79). Mahwah, NJ: Lawrence Erlbaum.

McBride, A. B. (1990). Mental health effects of women's multiple roles. American Psychologist, 45, 381-384.

Mead, G. H. (1934). Mind, self, and society: From the standpoint of a social behaviorist. Chicago: University of Chicago Press.

Oettingen, G. (1996). Positive fantasy and motivation. In P. M. Gollwitzer \& J. A. Bargh (Eds.), The psychology of action: Linking cognition and motivation to behavior (pp. 236-259). New York: Guilford.

Ovsiankina, M. (1928). Die Wiederaufnahme unterbrochener Handlungen. Psychologische Forschung, 11, 302-379.

Pyszczynski, T., Greenberg, J., \& Solomon S. (1997). Why do we need what we need? A terror management perspective on the roots of human social motivation. Psychological Inquiry, 8, 1-20.

Raynor, J. O. (1982). A theory of personality functioning and change. In J. O. Raynor \& E. E. Entin (Eds.), Motivation, career striving, and aging (pp. 249302). Washington, DC: Hemisphere.

Raynor, J. O., \& Entin, E. E. (1982). Theory and research on future orientation and achievement motivation. In J. O. Raynor \& E. E. Entin (Eds.), Motivation, career striving, and aging (pp. 13-82). Washington, DC: Hemisphere.

Rosenberg, M. (1965). Society and the adolescent self-image. Princeton, NJ: Princeton University Press.

Ruble, D. N. (1994). A phase model of transitions: Cognitive and motivational consequences. In M. Zanna (Ed.), Advances in experimental social psychology (pp. 163-214). New York: Academic Press.

Scherer, M. (1999). Selbstergänzung vs. Selbstwerterböhung. Unpublished master's thesis, Universität Konstanz, Germany.

Sedikides, C. (1995). Central and peripheral self-conceptions are differentially influenced by mood: Tests of the differential sensitivity hypothesis. Journal of Personality and Social Psychology, 69, 759-777.

Seifert, A. (1999). Effekte sozialer Realisierung von Absicbten und Vorsätzen auf ihre Ausfübrung. Unpublished master's thesis, Universität Konstanz, Germany.

Showers, C. J. (1992). Compartmentalization of positive and negative self-knowledge: Keeping bad apples out of the bunch. Journal of Personality and Social Psychology, 62, 1036-1049. 
Showers, C. J., \& Kling, K. C. (1996). Organization of self-knowledge: Implications for recovery from sad mood. Journal of Personality and Social Psychology, $70,578-590$.

Steele, C. M. (1988). The psychology of self-affirmation: Sustaining the integrity of the self. In L. Berkowitz (Ed.), Advances in experimental social psychology (Vol. 21, pp. 261-302). New York: Academic Press.

Stryker, S., \& Statham, A. (1985). Symbolic interaction and role theory. In G. Lindzey \& E. Aronson (Eds.), Handbook of social psychology (Vol. 1, pp. 311378). New York: Random House.

Suls, J. (Ed.). (1993). Psychological perspectives of the self (Vol. 4). Hillsdale, NJ: Lawrence Erlbaum.

Suls, J., \& Greenwald, A. G. (Eds.). (1983). Psychological perspectives of the self (Vol. 2). Hillsdale, NJ: Lawrence Erlbaum.

Swann, W. B., Jr. (1983). Self-verification: Bringing social reality into harmony with the self. In J. Suls \& A. G. Greenwald (Eds.), Psychological perspectives of the self (Vol. 2, pp. 33-66). Hillsdale, NJ: Lawrence Erlbaum.

Taylor, S. E., \& Brown, J. D. (1988). Illusion and well-being: A social psychological perspective on mental health. Psychological Bulletin, 103, 193-210.

Taylor, S. E., \& Gollwitzer, P. M. (1995). The effects of mind-sets on positive illusions. Journal of Personality and Social Psychology, 69, 213-226.

Tesser, A. (1988). Toward a self-evaluation maintenance model of social behavior. In L. Berkowitz (Ed.), Advances in experimental social psychology (Vol. 21, pp. 181-227). New York: Academic Press.

Tesser, A., Martin, L. L., \& Cornell, D. P. (1996). On the substitutability of self-protective mechanisms. In P. M. Gollwitzer \& J. A. Bargh (Eds.), The psychology of action: Linking cognition and motivation to behavior (pp. 48-68). New York: Guilford.

Tesser, A., \& Rosen, S. (1975). The reluctance to transmit bad news. In L. Berkowitz (Ed.), Advances in experimental social psychology (Vol. 8, pp. 193-232). New York: Academic Press.

Triandis, H. C. (1989). The self and social behavior in differing cultural contexts. Psychological Review, 96, 506-520.

Wagner, U., Wicklund, R. A., \& Shaigan, S. (1990). Open devaluation and rejection of a fellow student: The impact of threat to a self-definition. Basic and Applied Social Psychology, 11, 61-76.

Wicklund, R. A., \& Gollwitzer, P. M. (1981). Symbolic self-completion, attempted influence, and self-deprecation. Basic and Applied Social Psychology, 2, 89-114.

Wicklund, R. A., \& Gollwitzer, P. M. (1982). Symbolic self-completion. Hillsdale, NJ: Lawrence Erlbaum.

Wurf, E., \& Markus, H. (1991). Possible selves and the psychology of personal growth. In R. Hogan (Series Ed.) \& D. J. Ozer, J. M. Healy, \& A. Stewart (Vol. Eds.), Perspectives in personality: Self and emotion (Vol. 3A, pp. 39-62). London: Kingsley. 